\title{
Trends in Hospitalization Associated with TBI in an Urban Level 1 Trauma Centre
}

\author{
Elaine de Guise, Joanne LeBlanc, Jehane Dagher, Simon Tinawi, \\ Julie Lamoureux, Judith Marcoux, Mohammed Maleki, Mitra Feyz.
}

\begin{abstract}
Objective: Traumatic brain injury (TBI) is the single largest cause of death and disability following injury worldwide. The aim of this study was to determine the demographic, clinical, medical and accident related trends for patients with TBI hospitalized in an urban Level 1 Trauma Centre. Methods: Data were retrospectively collected on individuals $(\mathrm{n}=5,642)$ who were admitted to the Traumatic Brain Injury Program of the McGill University Health Centre - Montreal General Hospital from 2000 to 2011 . Results: Regression analysis showed a significant upward trend in the yearly number of cases as well as an upward trending by year in the proportion of TBI cases aged 70-years-old or more. The Injury Severity Scale scores were positively associated with year indicating a slight increase in injury severity over the years and there was an increase in patient psychological, social and medical premorbid complexity. In addition, the Extended Glasgow Outcome Scale score tended to become more severe over the years. There was a slight decrease in the proportion of discharges home and in the proportion of deaths. Conclusions: These results will help to understand the impact of TBI in an urban Canadian Level 1 Trauma Centre. This information should be used to develop public prevention strategies and to educate the community about the risk of TBI especially the risk of falls in the ageing population. These findings can also provide information to help health policy makers plan for future resources.
\end{abstract}

RÉSUMÉ: Hospitalisation associée à un traumatisme cérébral dans un centre urbain de traumatologie de niveau 1. Objectif : Le traumatisme cérébral (TC) est la plus grande cause de décès et d'invalidité après un traumatisme à travers le monde. Le but de cette étude était de déterminer les tendances démographiques, cliniques, médicales et en lien avec l'accident chez des patients atteints d'un TC hospitalisés dans un centre urbain de traumatologie de niveau 1. Méthode : Les données ont été recueillies rétrospectivement au sujet des individus $(\mathrm{n}=5$ 642) qui ont été admis au Programme de traumatisme cranio-cérébral du Centre hospitalier de l’Université McGill - Hôpital général de Montréal de 2000 à 2011 . Résultats : L'analyse de régression a montré qu'il existait une tendance significative à la hausse dans le nombre annuel de cas ainsi qu'une tendance à la hausse par année dans la proportion de cas de TC âgés de 70 ans et plus. Les scores au Injury Severity Scale étaient associés positivement à l'année indiquant une légère augmentation de la sévérité des blessures au fil des ans et une augmentation de la complexité des pathologies psychologiques, sociales et médicales prémorbides. De plus, nous avons noté une tendance à la hausse du score au Extended Glasgow Outcome Scale avec le temps. Il y avait une légère diminution de la proportion de congés hospitaliers avec retour à domicile et de la proportion de décès. Conclusions : Ces résultats aideront à comprendre l'impact du TC dans un centre urbain de traumatologie de niveau 1. Cette information devrait être utilisée pour développer des stratégies de prévention publique et pour éduquer la communauté sur le risque de TC, particulièrement le risque de chutes, dans la population âgée. Ces constatations peuvent également aider à la planification des ressources par les responsables des politiques de santé.

Can J Neurol Sci. 2014; 41:466-475

Traumatic brain injuries are sudden and devastating, posing considerable consequences to patients, to their families and to the health care system. Persons who sustain a traumatic brain injury (TBI) undergo an abrupt transformation from living in a healthy state to surviving a life-threatening situation to eventually coping with a state of chronic illness ${ }^{1}$.

Traumatic brain injury is a leading cause of death and disability among persons in the United States. A 2010 report by the Centers for Disease Control and Prevention revealed that an estimated 1.7 million people sustain a TBI in the United States each year. This is an increase compared to the 2004 estimate which was 1.4 million TBI-related injuries. Of this number, 52,000 died from their TBI and 275,000 were hospitalized. Adults aged 75 years and older had the highest rates of TBIrelated hospitalization and death. The report also indicated that the rate of TBI was higher for males than for females. When focusing on etiologies of TBI, falls were the leading cause among adults aged 65 years and older and represented approximately $60.7 \%$ of all $\mathrm{TBIs}^{2}$. Motor vehicle-traffic incidents were the second leading cause of TBI $(17.3 \%)$ and resulted in the largest percentage of TBI-related deaths $(31.8 \%)$. Assaults made up $10 \%$ of TBIs in the population ${ }^{2}$.

From the Neurology and Neurosurgery Department (EdG, JM, MM), Traumatic Brain Injury Program (JLB, JD, ST, MF), Physical Medicine and Rehabilitation Service (JD, ST), McGill University Health Centre; Psychology Department (EdG), Social and Preventive Medicine Department (JL), University of Montreal, Montreal, Quebec, Canada.

Received October 18, 2013. Final Revisions Submitted January 14, 2014. Correspondence to: Elaine de Guise, Traumatic Brain Injury Program, McGill University Health Centre, Montreal General Hospital site, Room D13-124, 1650 Cedar Avenue, Montreal, Quebec, H3G 1A4, Canada. Email: elaine.de.guise@umontreal.ca. 
In Canada, a 2006 report by the Canadian Institute for Health Information (CIHI) detailed that there were 16,811 TBI-related hospitalizations in 2003-2004. Among these, 1,368 individuals died following their TBI, which represents $8 \%$ of TBI admissions. The number of deaths varied significantly between age groups, with the majority occurring in the elderly (59\%). Between the years 2003 and 2004, falls were one of the most prevalent causes of injury leading to hospitalizations in Canada (45\%) followed by motor vehicle crashes $(23 \%)^{3}$.

Some encouraging statistics demonstrate a general decrease in admissions related to TBI. This is true for Canada, where TBIrelated admissions for all ages have declined except for the group of patients aged 60 years and over, for whom the incidence of TBI-related admissions has increased at a rate of $4 \% 3$. Also, a decrease in the hospitalization rate for children and young adults and a stable rate for adults aged 66 years and older was reported by a Canadian research group ${ }^{4}$. This decline in admission rate could partly be due to the success of prevention programs as well as the shift of care from in-patient to out-patient settings for patients with less severe $\mathrm{TBI}^{5}$. However, a study from the United States, by the Centers for Disease Control and Prevention in $2006^{2}$ showed an increase in TBI-related hospitalizations (19.5\%) from 2002 to 2006 which may have been related to age. More precisely, there was an increase in fall-related TBIs among adults aged 65 and older, a $34 \%$ increase in hospitalizations, and a $27 \%$ increase in TBI-related deaths in this period. Moreover, other findings from Sweden ${ }^{6}$, showed a higher rate of TBIrelated admissions for older men with mild TBI presenting an acute or chronic subdural hematoma following a fall ${ }^{6}$.

Based on the literature, age seems to represent a significant factor influencing outcome following TBI. In Canada, the number of people aged 65 and over increased by $14.1 \%$ between 2006 and 2011 to nearly five million and accounted for a record high of $14.8 \%$ of the population in Canada in $2011^{3}$. The present study will provide more information regarding TBI-related age trends that have occurred over the last decade in a Canadian Level 1 Trauma Centre. Other variables such as psychological, medical and cognitive premorbid status as well as psychosocial history will also be analysed to help obtain a more comprehensive portrait of the TBI population hospitalized in the TBI program of the McGill University Health Centre -Montreal General Hospital (MUHC-MGH), a Canadian urban Trauma Centre. For instance, it is generally assumed that anxiety, depression and substance use are more prevalent in urban than in rural dwellers ${ }^{7}$. Substance abuse, homelessness and violence are also felt to be more common ${ }^{8}$. It will be interesting to see how prevalent these characteristics are in the TBI population of the MUHC-MGH. This analysis of TBI population trends will be beneficial for planning of professional and material resources required for the future in order to meet the needs of patients and their families.

The present study examined data from the MUHC-MGH TBI program. This program provides specialized and superspecialized acute care and early rehabilitation to adult neurotrauma patients regardless of etiology and severity of brain injury and ensures the continuity of their care in order to enhance potential for social reintegration. The TBI Program promotes a holistic, comprehensive and interdisciplinary approach as the hallmark of its professional care. Clinical activities include acute neurotrauma care with early rehabilitation emphasizing accessibility, precocity, efficiency, quality, continuity and durability of outcome through the continuum of care.

The aim of this study was to describe and assess the significance of the demographic, clinical, medical and accident related trends for patients with TBI hospitalized at an urban Level 1 Trauma Centre.

\section{MethoDS}

\section{Subjects}

A total of 5,642 patients diagnosed with a TBI by a physician were admitted to the TBI Program of the MUHC-MGH between 2000 and 2011 and were included in the study. Radiographic evidence of a brain lesion was considered sufficient to confirm the presence of a TBI. If brain imaging was negative, two indicators among the ones described next were deemed necessary to diagnose TBI: loss of consciousness, alteration of level of consciousness (diminished Glasgow Coma Scale (GCS) score), amnesia of the event and major facial or extra-cranial damage. In our Level 1 Trauma Centre, patients with mild TBI are admitted for observation for at least 48 hours if one of the following is observed: positive computed tomogram (CT) of the brain with the presence of a traumatic injury, basal skull fracture, open skull fracture, past medical history of mild TBI with PTA of $\geq 60$ minutes, post traumatic convulsion, $\geq 3$ episodes of vomiting, multiple complex facial fractures, mild TBI associated with another major traumatic injury, i.e.: orthopedic, abdominal, etc., age of 65 years or more and living alone, and patient on anticoagulation therapy. Approval for this retrospective study was granted by the research ethics board of the MUHC-MGH.

\section{Variables measured}

Demographic characteristics. Gender (male or female), age (ordinal variable), preferred language (French/others) and marital status (single, divorced, married, living as a couple, separated, widowed) were examined.

Medical and accident related characteristics. The Injury Severity Score (ISS) and GCS were gathered. Glasgow Coma Scale score upon admission to the emergency room was used to determine severity of the TBI. A GCS score of 13-15 reflected a mild TBI, 9-12 a moderate TBI, while a score of 3-8 indicated a severe TBI. Moreover, the etiologies of trauma as related to the type of insurance coverage were examined (motor vehicle accident-SAAQ, work accident-CSST, criminal act-IVAC, FallsRAMQ).

Clinical characteristics. A complexity score was computed by adding the number of complicating factors. These included a positive brain CT-Scan, past medical history of substance abuse, neurological, sensory or intellectual impairments, severe behavioral issues, psychiatric diagnosis, geriatric profile (loss of autonomy), dementia, suicidal attempts and homelessness.

\section{Outcome variable}

\section{Length of Stay}

Length of stay (LOS) corresponded to the number of days the patient remained hospitalized in the acute care setting from admission to discharge. 


\section{The Extended Glasgow Outcome Scale (GOSE) ${ }^{9}$}

The GOSE assesses global outcome. On this scale, scores of 7 or 8 correspond to good recovery, referring to normal participation in social, vocational and physical life. Scores of 5 or 6 indicate moderate disability, describing the patient who is independent but physically or cognitively disabled and requiring an altered physical, social, psychological or vocational environment for participation. Patients with severe disabilities receive scores of 3 or 4 and are totally dependent in managing a normal or modified environment, whereas a score of 2 corresponds to a vegetative state reflecting total dependency with no awareness of the environment. Patients who died receive a score of 1 . This rating was given only once the patient was discharged from the acute care setting by the members of the TBI multidisciplinary team who were involved in the care of the patient.

\section{Discharge Destination}

Discharge destinations included home without rehabilitation services, in-patient rehabilitation, out-patient rehabilitation, long-term care residence and death. Since 1994, referral to rehabilitation programs is carried out within an organized consortium of care mandated by the Quebec Ministry of Health and Social Services and consisting of a grouping of nine institutions providing acute care, post-acute and outpatient specialized rehabilitation for patients recovering from moderate and severe brain injuries, six regional health boards, and the Quebec Traumatic Brain Injury Association which provides community based services.

\section{Statistical analysis}

Descriptive statistics are presented as means and standard deviations for numerical variables and proportions for categorical variables. Bivariate associations between nominal variables were calculated using chi-square statistics. For ordinal or numeric variables, bivariate associations were carried out using the appropriate correlation coefficients. Trends for numerical variables were determined using linear regressions whereas we used odds ratios to quantify trends for ordinal and dichotomous variables. When isolating marginal effects by year, we used either logistic regressions (dichotomous outcomes), ordinal regressions (ordinal outcomes), Poisson regressions (count outcomes) or linear regressions (numerical outcomes). All tests were performed at the 0.05 level of significance using Stata 12.0 (StataCorp Inc.). Bonferroni corrections were used for all post-hoc comparisons.

\section{RESULTS}

\section{Annual number of TBI cases}

There was a total of 5,642 cases for which data were collected over the span of 12 years. The number of TBI cases by year is presented in Figure 1. There was a significant trend upwards in the yearly number of cases $(b=29.094, p<0.001)$, with an increase of 29 patients a year on average $(95 \% \mathrm{CI}=[24.9 ; 33.3])$ between the years 2000 and 2011 .

\section{Numbers of TBI cases per month and day}

Figure 2 shows the evolution of the number of cases per month of admission for the years 2000 to 2011. There was a significant relationship between month of admission and year $\left(\chi_{121 \mathrm{df}}^{2}=181.884, \mathrm{p}<0.001\right)$. The high volume months were during the summer time.

Figure 3 shows the pattern of the number of cases admitted by day of the week for the years 2000 to 2011 . There was no significant variation from year to year in the proportion of admissions according to the day of the week as indicated by a non-significant chi-square between day and year $\left(\chi_{72 \mathrm{df}}^{2}=\right.$ $57.137, \mathrm{p}=0.900)$. High admission volume days were Fridays, Saturdays and Sundays. A significant difference in the number of admissions is shown from day to day $\left(\chi_{6 \mathrm{df}}^{2}=22.224, \mathrm{p}=0.001\right)$, the highest proportion being on Saturday with $16.6 \%$ of all admissions that day. However, the severity of the cases admitted

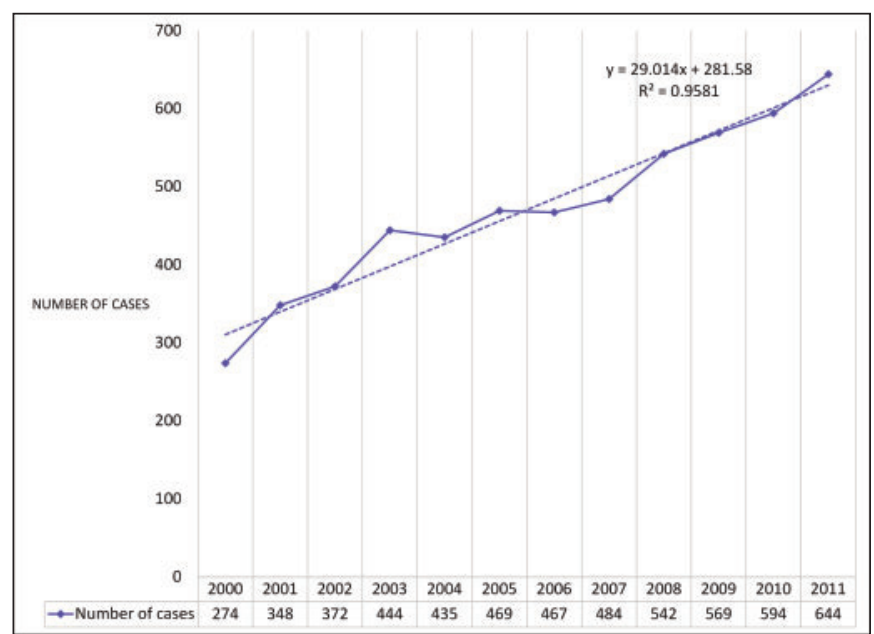

Figure 1: Trend in annual number of TBI cases between 2000 and 2011 $(n=5,642)$.

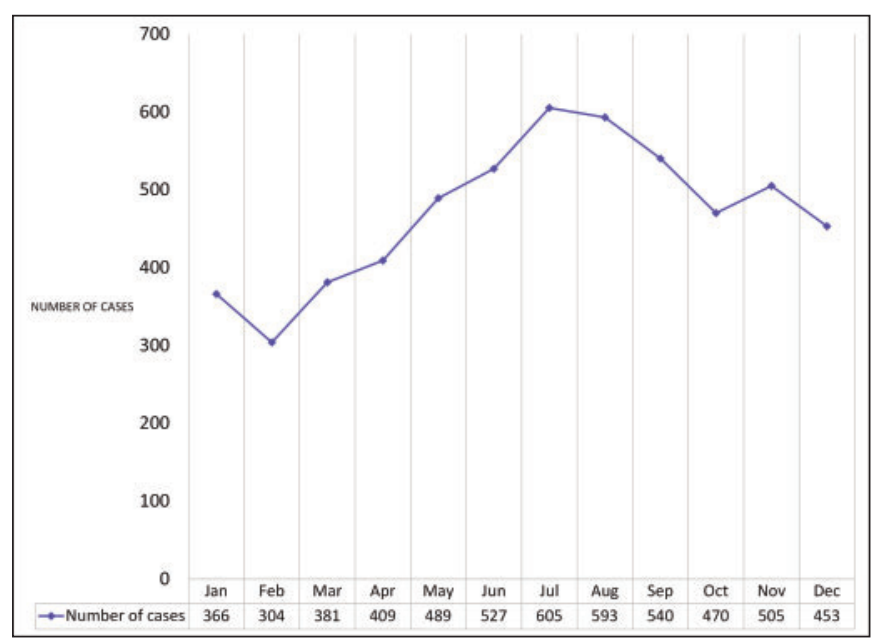

Figure 1: Number of admissions per month $(n=5,642)$ 


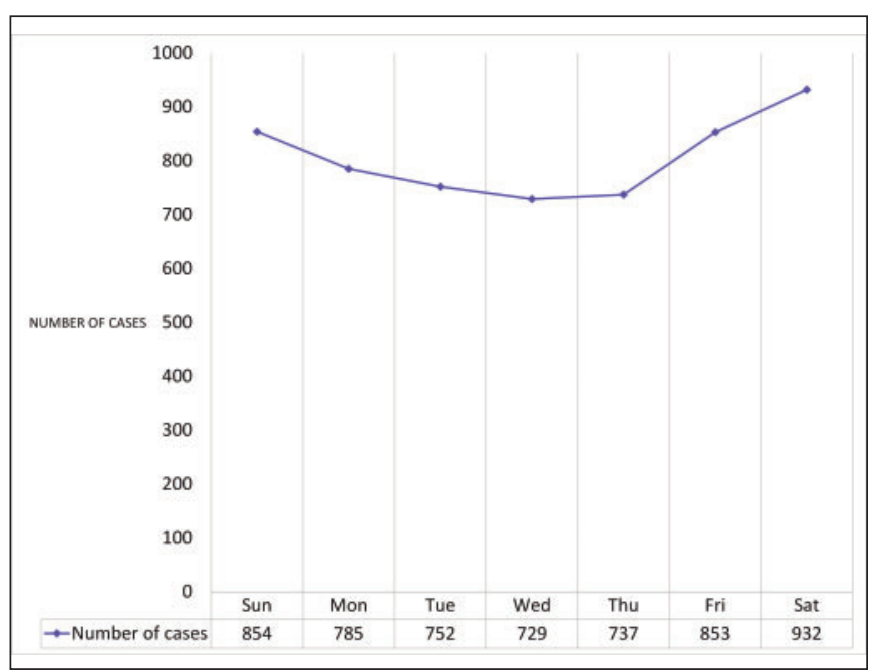

Figure 3: Number of admissions by day of the week between 2000 and $2011(n=5,642)$

did not vary significantly between admission days $\left(\chi_{12 \mathrm{df}}^{2}=\right.$ 18.326, $\mathrm{p}=0.106$ ).

There was an association between the injury mechanism /insurance type and the day of admission $\left(\chi_{18 \mathrm{df}}^{2}=94.162, \mathrm{p}<\right.$ $0.001)$. Overall, the percentage of individuals involved in a work accident (CSST) was $4.9 \%$. There was a significantly lower proportion of work-related events on Saturdays (3.2\%) and Sundays $(2.7 \%)$, and a higher percentage on Tuesdays $(7.2 \%)$ and Thursdays (8.3\%). Also, the overall percentage of assaultrelated TBIs (IVAC) was $10.4 \%$. There was a significantly higher proportion of this latter group on Saturdays (13.5\%) and Sundays (14.4\%), and a lower percentage on Wednesdays $(6.9 \%)$ and Thursdays $(6.6 \%)$. Moreover, there was a significant association between the day of the week and the average age of

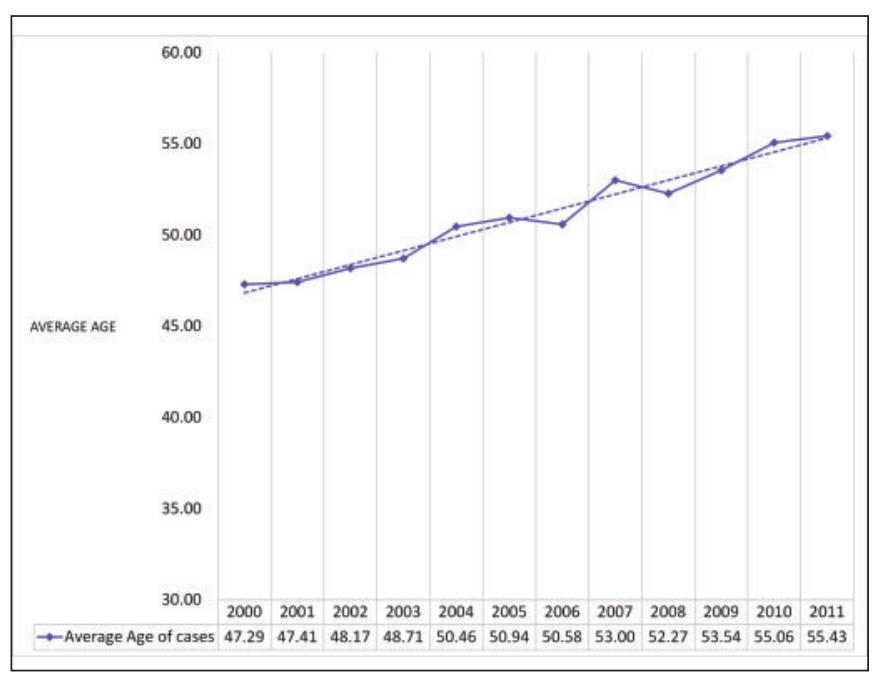

Figure 5: Trending for average age of cases by year $(n=5,639)$

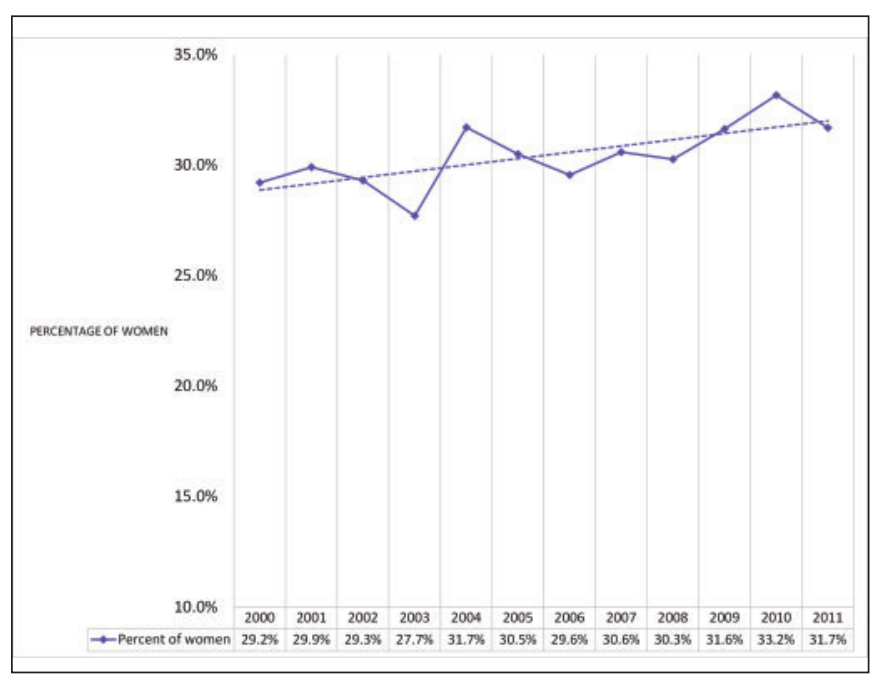

Figure 4: Trend in the proportion of women per year $(n=5,642)$

patients $\left(\mathrm{F}_{(6,5632)}=9.19, \mathrm{p}<0.001\right)$ and post-hoc comparisons with Bonferroni corrections for multiple tests pointed out that the average age was significantly lower by about four to five years on Saturdays and Sundays compared to Mondays through Thursdays.

\section{Gender}

Figure 4 shows that women represented an average of $30 \%$ of hospitalizations following TBI. Although this proportion seemed to trend upwards over the years, the association was not significant $(\mathrm{OR}=1.014, \mathrm{p}=0.097,95 \% \mathrm{CI}=[0.997 ; 1.032])$.

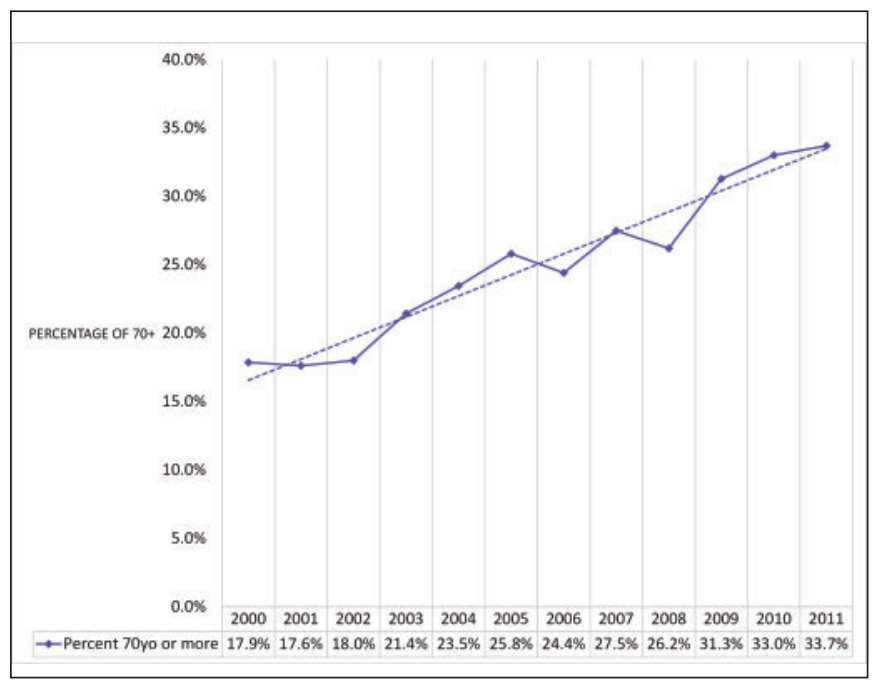

Figure 6: Trending for percentage of cases 70 years of age or more by year $(n=5,639)$ 


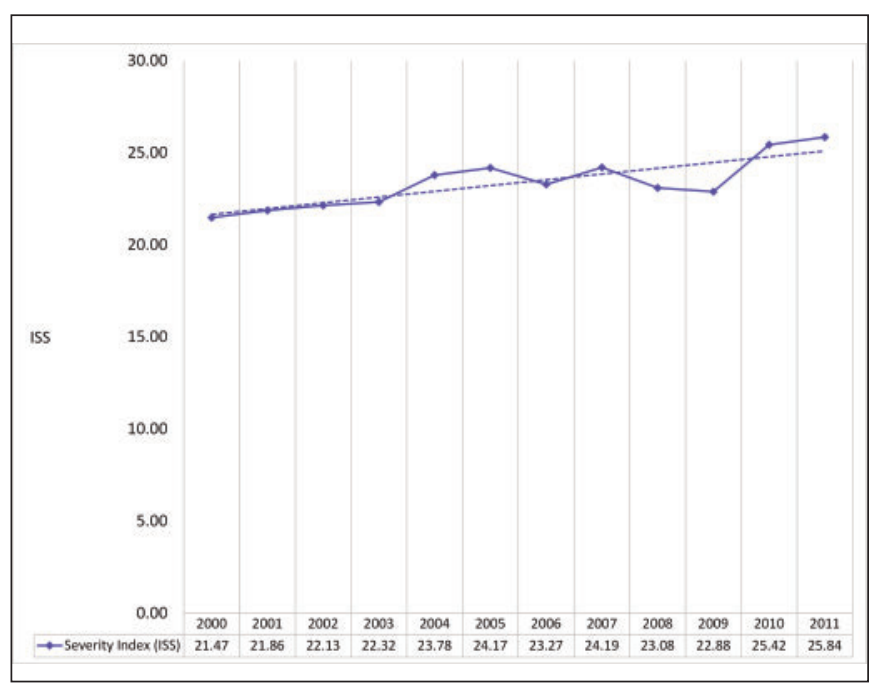

Figure 7: Trending of the average ISS score by year $(n=5,326)$

Age

Figure 5 shows the trending upward for average age between the years 2000 and 2011. In fact, the Pearson correlation between age and year was significant and positive $(r=0.132, p<0.001)$. Figure 6 shows the upward trending by year in the proportion of TBI cases that were aged 70 -years-old or more. This trend was significant with the odds of being aged 70 or more increasing by about $9 \%$ each year $(\mathrm{OR}=1.086, \mathrm{p}<0.001,95 \% \mathrm{CI}=$ $[1.067 ; 1.106])$.

\section{Language preference}

The proportion of TBI cases using French as their preferred language was $60.5 \%$. There was no significant change in the distribution of preferred language over the years $(\mathrm{OR}=0.992, \mathrm{p}$ $=0.387,95 \% \mathrm{CI}=[0.974 ; 1.010])$.

\section{Marital status}

Although a chi-square indicated significant differences between the years $\left(\chi_{42 \mathrm{df}}^{2}=984.391, \mathrm{p}<0.001\right)$, these differences in marital status were probably due to the large sample size and do not represent linear trends. The hospitalized patients were mainly single $(\sim 60 \%)$ or married $(\sim 30 \%)$.

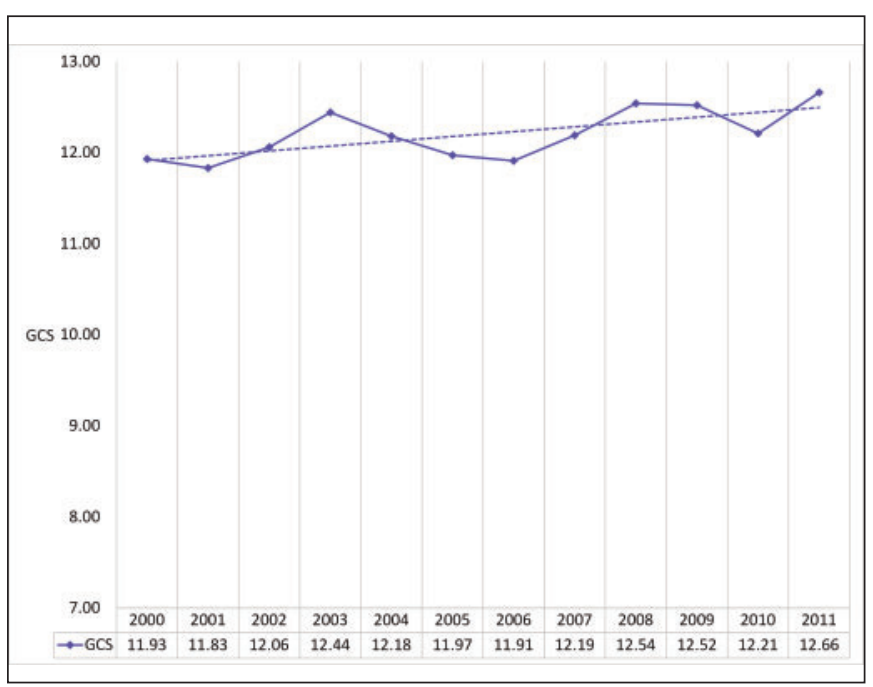

Figure 8: Trending of average GCS score by year $(n=5,556)$

\section{Medical and accident related characteristics}

\section{Injury severity scale}

Figure 7 shows the trends in the average ISS score per year. The ISS score was positively associated with year $(r=0.097, p$ $<0.001$ ) indicating a slight but significant increase in ISS scores between the years 2000 and 2011. A linear regression was performed to determine if this trend persisted after controlling for age and gender mix. The results of this regression are given in Table 1 and show that for everything being equal, the ISS scores were lower for women by an average of 1.17 points $(95 \%$ $\mathrm{CI}=[0.552 ; 1.778])$ and that age was not a significant predictor of ISS score. Despite the control for age and gender mix, there was a significant positive association between year and ISS score, the ISS score increasing by about 0.3 every year $(95 \% \mathrm{CI}$ $=[0.220 ; 0.390])$.

\section{Glasgow Coma Scale scores}

Figure 8 gives the trending of the average GCS score by year. It appears as though the average GCS score is trending upward, indicating an overall milder severity. Figure 9 which presents the percentage of patients in the different severity categories, shows a similar tendency, a higher proportion of mild TBI cases as the

Table 1: Results of the regression on ISS scores after controlling for age and gender mix $(n=5,326)$

\begin{tabular}{l|c|c|c|c|cc}
\hline ISS total & $\begin{array}{c}\text { Coefficient } \\
(\mathrm{b})\end{array}$ & $\begin{array}{c}\text { Standard } \\
\text { error }\end{array}$ & $\mathrm{t}$ & Sig & \multicolumn{2}{|c}{ [95\% Conf. Interval] } \\
\hline Year & .304 & .043 & 7.02 & 0.000 & .2197058 & .3900822 \\
\hline Women & -1.165 & .312 & -3.73 & 0.000 & -1.777716 & -.5523576 \\
\hline Age & .006 & .006 & 0.97 & 0.333 & -.0064151 & .0189582 \\
\hline Constant & -588.063 & 87.144 & -6.75 & 0.000 & -758.9016 & -417.2253 \\
\hline
\end{tabular}




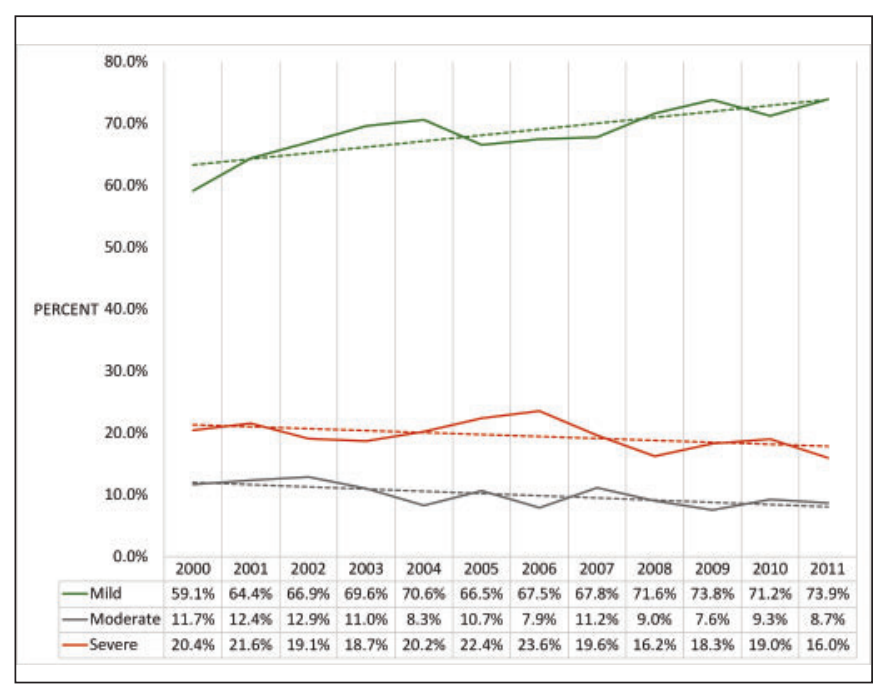

Figure 9: Trending in severity of trauma $(n=5,556)$

years go by. Trending indicated an increase in the proportion of mild TBI of about 1.3 percentage points every year. This decrease in severity could have been due to a different population mix from year to year. Therefore, an ordered logistic regression was performed to determine if this relation between year and severity was present after controlling for gender and age mix. The results indicated that the risk of having a TBI of greater severity was higher for men $(\mathrm{OR}=1.231,95 \% \mathrm{CI} \mathrm{OR}=$ [1.082;1.399]) and for those under the age of $70(\mathrm{OR}=1.300$, $95 \%$ CI OR $=[1.134 ; 1.491])$. Controlling for these factors, the odds of having a more severe TBI were still significantly associated with year, those odds decreasing as the years went by $(\mathrm{OR}=0.970,95 \% \mathrm{CI}$ OR $=[0.954 ; 0.987])$.

\section{Etiologies/insurance coverage}

Overall, the distribution of etiologies as related to insurance coverage was the following: $52.1 \%$ were related to falls/RAMQ. $32.7 \%$ to motor vehicle accidents/SAAQ, $4.9 \%$ to work accidents/CSST and $10.3 \%$ stemmed from assaults/IVAC. Figure 10 shows the upward trend in the proportion of falls/RAMQ insurance and the downward trend in the proportion of motor vehicle accident/SAAQ cases.

According to this graph, the relative increase in numbers from year to year was greater for falls/RAMQ cases (there were about three times more falls/RAMQ patients in 2011 compared to 2000) than for any other type of mechanism/insurer. For motor vehicle accidents/SAAQ and assaults/IVAC cases, the number of cases was a little less than two times more in 2011 compared to 2000; for work accidents/CSST cases, the number of cases was about the same from year to year.

Bivariately, the odds of having a more severe TBI (as measured by the GCS) were significantly higher for trauma resulting from a car accident $(\mathrm{OR}=1.190,95 \% \mathrm{CI}$ [1.050;1.349]) compared to that secondary to a fall while the odds of having a more severe TBI were significantly lower in the work related trauma group $(\mathrm{OR}=0.613,95 \% \mathrm{CI}[0.450 ; 0.836])$

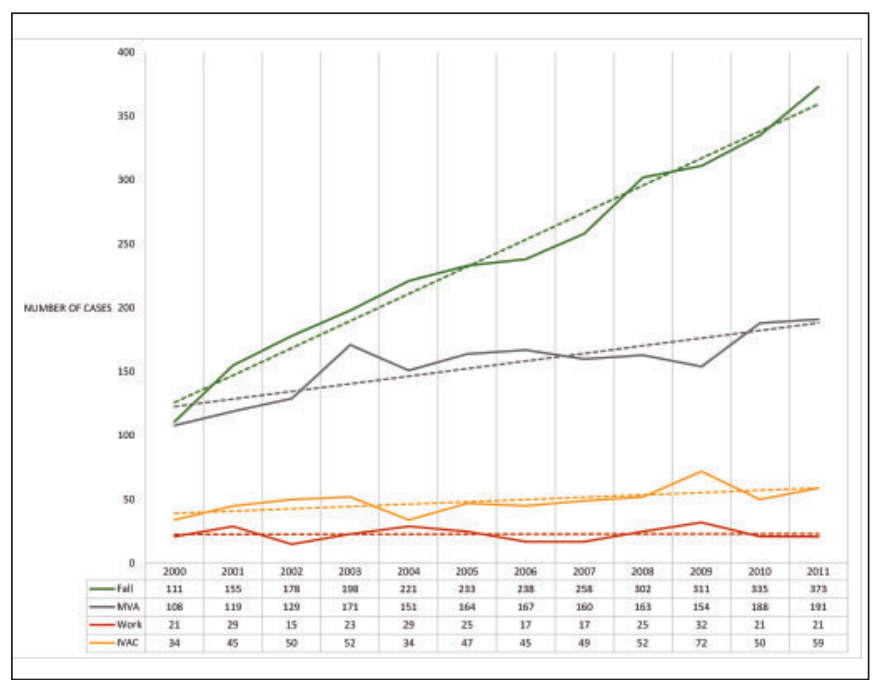

Figure 10: Trend in etiologies by year $(n=5,642)$

compared to the fall group. There were no significant differences in severity between fall related TBIs andTBI as a result of a criminal act.

An analysis of variance (ANOVA) $\left(\mathrm{F}_{(3.5322)}=43.00, \mathrm{p}<\right.$ $0.0001)$ indicated that ISS scores were significantly different between the various etiology groups. A Bonferroni corrected post-hoc test showed that all groups had significantly different ISS scores except for work accidents/CSST and falls/RAMQ which did not show any difference. Assault-IVAC insured traumas had the lowest ISS scores, followed by RAMQ and CSST insured traumas and finally SAAQ insured traumas.

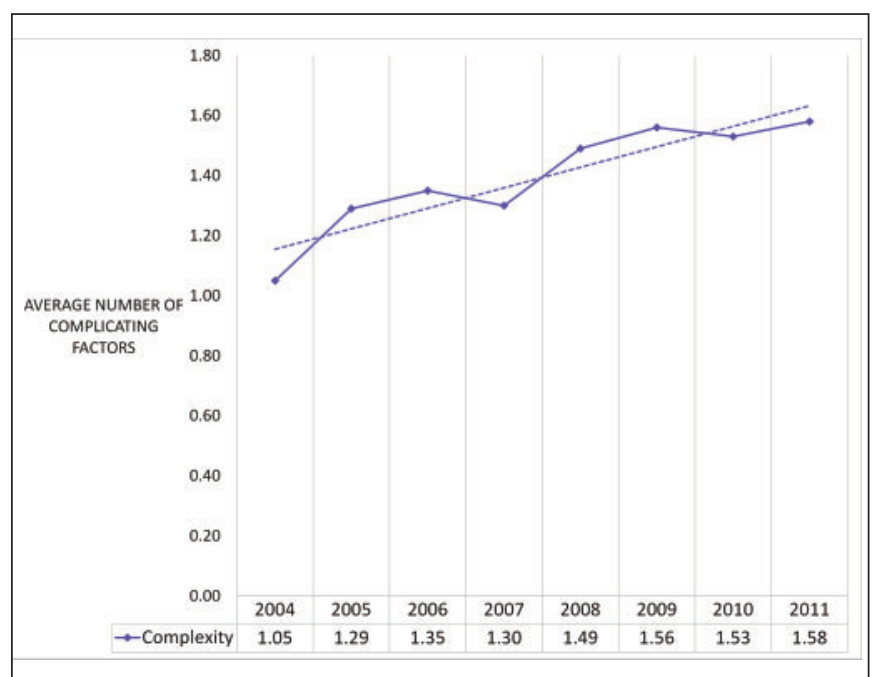

Figure 11: Trending for average number of complicating factors per case by year $(n=3,106)$ 


\section{Complexity}

An ad hoc complexity score was computed for all relevant cases presenting complicating factors. When a patient presented with no complicating factors, the case received a score of 0 . The total score was obtained by adding the number of complicating factors and varied between 0 and 6 with a mean of 1.5 with a standard deviation of \pm 1.0 . This score is used in our institution to describe the number of complicating factors present in the medical history (positive CT-scan, previous neurological condition, previous intellectual impairment, geriatric profile, dementia, previous sensory deficit, previous behavioural problems, previous psychiatric disorder, history of substance abuse, previous suicide attempt, homelessness) and its metric properties have not been tested. It is important to mention that the data regarding complicating factors were not available before 2003 , resulting in a large number of missing values. The results showed that $62.8 \%$ of patients had a positive CT-Scan, $19.4 \%$ had a previous neurological condition, $0.7 \%$ had a previous intellectual impairment, $4.8 \%$ had a geriatric profile, $3.5 \%$ had previous dementia, $3.3 \%$ had a previous sensory deficit, $1.7 \%$ had previous severe behavioral problems, $18.7 \%$ a previous psychiatric disorder, $29.2 \%$ a substance abuse antecedent, $1.6 \%$ previous suicidal attempts and $2.9 \%$ were homeless. Figure 11 shows the average number of complicating factors by year. There was a significant correlation between the number of complicating factors and year (Spearman rank correlation $\mathrm{r}=$ $0.103, \mathrm{p}<0.001)$. This correlation showed a significant increase in the number of complicating factors as the years went by. A Poisson regression, controlling for factors like age, gender, etc. indicated that every year, the log of the expected number of complicating factors increased by 0.04 units. This means that, for everything else being equal, each year the incidence rate ratio for the number of complicating factors could be expected to increase by a factor of 1.04. Complexity also increased with patient age, ISS score and trauma severity. It was lower for women and for patient victim of a fall.

\section{Outcome measure trends}

\section{Length of stay}

An upward trend for LOS between the years 2000 to 2011 was observed. A regression analysis was performed in order to determine if this increase was present after controlling for case mix. First, LOS was not normally distributed and we performed a log transformation to correct this situation before running the regression. The variables considered for control in the linear regression were age, gender, language, insurance type, severity of the TBI, ISS score, discharge destination, leaving against medical advice (AMA), weekend admission and the year of the trauma. The results of this first regression are listed in Table 2. It shows that LOS was significantly longer for older patients, for those with a higher ISS, for more severe TBIs, for those admitted on the weekend and for men. It also indicated that all subjects discharged anywhere else but home had a longer LOS except for those who died. Of course, those leaving AMA had a significantly shorter LOS. After controlling for all these variables, LOS showed a small but significant decrease from one year to the next. It was clear that LOS is shorter now than it was in the past for subjects of the same age, same gender, with the same injury severity and the same discharge location. This model explained $40 \%$ of the variability of LOS.

\section{The Extended Glasgow Outcome Scale}

The distribution of the eight outcome categories of the GOSE (death, vegetative state, lower severe disability, upper severe disability, lower moderate disability, upper moderate disability, lower good recovery, upper good recovery) is shown in Table 3. The GOSE scores were not collected for $10 \%$ of the subjects (missing data) for different reasons (weekend discharges without assessment by the TBI team or patient not evaluated or followed by the TBI team). A Spearman rank correlation indicated a significant negative but weak correlation $\left(\mathrm{r}_{\text {Spearman }}=-0.085, \mathrm{p}<\right.$ 0.001 ) between GOSE and the year, revealing that the GOSE

Table 2: Results of the regression on $\operatorname{LOS}(n=5,250)$

\begin{tabular}{|c|c|c|c|c|c|}
\hline LOS total & Coefficient & Standard error & $\mathrm{t}$ & $P>|t|$ & [95\% Conf. Interval] \\
\hline Age & 0.005 & 0.001 & 8.15 & 0.000 & $.004 \quad .007$ \\
\hline Women & -0.072 & 0.027 & 2.66 & 0.008 & $\begin{array}{ll}-.126 & -.019 \\
\end{array}$ \\
\hline ISS & 0.023 & 0.001 & 17.01 & 0.000 & $.021 \quad .026$ \\
\hline Compared to mild severity & 0 & 0.0 & $\begin{array}{l}7.91 \\
5.96\end{array}$ & 0.000 & $\begin{array}{ll}.251 & .416 \\
148 & 293\end{array}$ \\
\hline $\begin{array}{r}\text { Compared to home discharge } \\
\text { Acute care hospital }\end{array}$ & 0.535 & 0.064 & 8.50 & 0.000 & $.423 \quad 677$ \\
\hline Death & -0.627 & 0.051 & -12.38 & 0.000 & $\begin{array}{rr}-.726 & -.528 \\
236 & 394\end{array}$ \\
\hline Outpatient rehabilitation & 0.315 & 0.040 & 7.80 & 0.000 & $.236 \quad .394$ \\
\hline Inpatient rehabilitation & 1.138 & 0.035 & 32.89 & 0.000 & $\begin{array}{ll}1.071 & 1.207 \\
\end{array}$ \\
\hline Long term care & 1.064 & 0.058 & 18.32 & 0.000 & $.950 \quad 1.178$ \\
\hline Year & -0.018 & 0.004 & -4.64 & 0.000 & $-.025-.010$ \\
\hline AMA discharge & -0.217 & 0.087 & -2.50 & 0.013 & $-.387-.047$ \\
\hline Weekend discharge & 0.070 & 0.024 & 2.85 & 0.004 & .022 .118 \\
\hline Constant & 36.124 & 7.586 & 4.76 & 0.000 & $21.252 \quad 50.997$ \\
\hline
\end{tabular}


Table 3: Distribution of GOSE original scores $(n=5,283)^{1}$

\begin{tabular}{r|c|c}
\hline \multicolumn{1}{l|}{ GOSE } & $\mathbf{n}$ & Death \\
\hline Vegetative state & 582 & 11.02 \\
\hline Lower severe disability & 139 & 1.44 \\
\hline Upper severe disability & 568 & 2.63 \\
\hline Lower moderate disability & 1581 & 10.75 \\
\hline Upper moderate disability & 2052 & 29.93 \\
\hline Lower good recovery & 285 & 38.84 \\
\hline Upper good recovery & 0 & 5.39 \\
\hline Total & $\mathbf{5 2 8 3}$ & $\mathbf{1 0 0 . 0 0}$ \\
\hline
\end{tabular}

${ }^{1}$ There were 378 missing values $(6.54 \%)$ for GOSE

score tended to decrease slightly (become more severe) over the years spanning between 2000 and 2011.

\section{Destination at discharge}

Results showed that overall $4.1 \%$ of patients were sent to another acute care hospital upon discharge, $11.1 \%$ died, $12.0 \%$ were sent to out-patient rehabilitation, $24.9 \%$ to an in-patient rehabilitation facility, $5.7 \%$ were discharged to a long-term care centre and $41.4 \%$ were sent home. There was a significant association between discharge disposition and year $\left(\chi_{55 \mathrm{df}}^{2}=\right.$ 178.972, $\mathrm{p}<0.001)$ but each destination would need to be investigated separately in order to determine where the differences lie. Figure 12 shows the trend for the proportion of TBI cases who died, were discharged home or to rehabilitation (the other destinations are not shown because there was no upward or downward trend). Looking only at the yearly trends in Figure 12, we notice a slight decrease in the percentage of discharges home and the percentage of deaths and a slight increase in the proportion of patients sent to either inpatient or outpatient rehabilitation.

More specifically regarding death, there was a very small but significant association (Spearman rank $\mathrm{r}=-0.032, \mathrm{p}=0.017$ ) between year and mortality, indicating a tendency for a decreasing mortality rate between the years 2000 and 2011. Bivariately, there was no association between gender and mortality $\left(\chi_{1 \mathrm{df}}^{2}=2.547, \mathrm{p}=0.111\right)$. Overall, the mortality rate for men was $11.6 \%$ and $10.1 \%$ for women. There was a significant association between mortality rate and trauma mechanism $\left(\chi_{3 \mathrm{df}}^{2}\right.$ $=35.275, \mathrm{p}<0.001)$. Mortality rate was $13.2 \%$ for falls, $10.2 \%$ for motor vehicle accidents, $6.6 \%$ for work accidents and $6.0 \%$ for assaults. Moreover, there was a significant positive association between mortality and ISS scores (Spearman rank $\mathrm{r}$ $=0.268, \mathrm{p}<0.001)$. There was also an association between mortality rate and TBI severity with $3.6 \%$ mortality in the mild group, $15.1 \%$ in the moderate group and $36.3 \%$ in the severe group $\left(\chi_{2 \mathrm{df}}^{2}=927.503, \mathrm{p}<0.001\right)$.

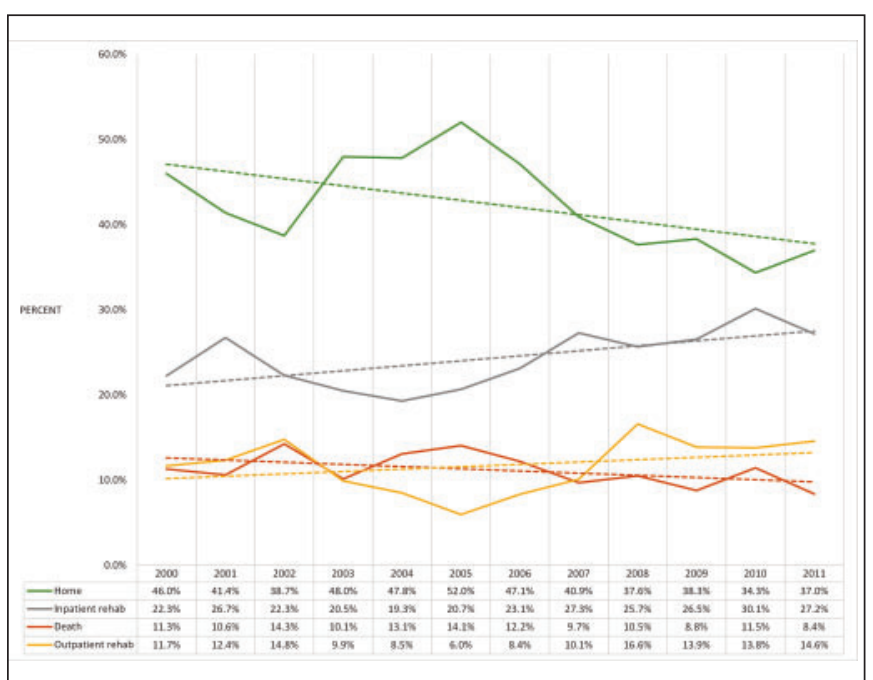

Figure 12: Trending of destination at discharge by year $(n=5,556)$.

\section{Discussion}

The aim of this study was to determine the trends for demographic, clinical, medical and accident related characteristics of patients with TBI hospitalized at an urban Level 1 Trauma Centre. The findings showed a significant upward trend in the yearly number of cases. The higher number of TBI hospitalizations at the MUHC-MGH could be in part related to better organization of care within the Quebec Trauma Network whereby victims of TBI are systematically directed to the emergency room of a tertiary trauma centre, instead of a nondesignated centre. As in a study done by an Italian group ${ }^{10}$, the high volume months were during the summer time and the high volume days were during weekends. This information would be pertinent to administrators and managers for staff scheduling. Globally, this upward trend in the yearly number of cases is in keeping with the 2004 findings of the Centers for Disease Control and Prevention ${ }^{2}$.

Another important finding of this study is that it showed an increase in the average age over the years and an increase in the number of patients aged 70-years-old and over. This is also supported by other research where an increase in the incidence of patients with TBI over 60-years-old was evident ${ }^{3,4}$. In a study from Finland, the incidence increased by $59.4 \%$ for patients aged 70 years or older while the incidence decreased by $2.4 \%$ in the younger age groups ${ }^{11}$. The increase of people aged 65 and over in the general population could explain this tendency in the TBI population. In Canada, people aged 65 and older now account for a growing proportion. Between 1986 and 2010, the number of Canadian seniors increased and the percentage went from $10 \%$ to $14 \%$ of the population ${ }^{12}$.

The demographic, clinical and accident related factors of the MUHC-MGH TBI clientele is very similar to what has been reported elsewhere. Previous studies found that men are twice as likely to experience a TBI as are women ${ }^{2,10,13,14}$. In the current work, women represented an average of $30 \%$ of the caseload, 
patients were mainly French speaking (60\%) and those hospitalized were mainly single $(\sim 60 \%)$ or married $(\sim 30 \%)$. The number of falls increased during this decade compared to the number of motor vehicle accidents, which is probably related to the fact that more patients were aged 70 and over. Faul et $a l^{2}$ also noted the same tendency regarding etiology with falls as the leading cause of TBI among adults aged 65 years and older and representing approximately $60.7 \%$ of all TBIs in this age group ${ }^{2}$. An increased incidence of TBI related to falls was also reported for the geriatric population by Seidler and colleagues ${ }^{15}$. Moreover, a study by Koskinen et al ${ }^{11}$ showed that for the oldest patients in their investigation, the most common external cause of TBI was falls.

Another finding of this study is an increase in trauma severity (ISS scores) over the years, which is an important consideration for administrators when planning for future resources. The exact reasons for the increase in ISS scores are not known but a contributing factor may be the systematic referral of the more severe cases to our tertiary trauma center, based on the strong recommendation by policy makers over the last years. In addition, we could hypothesize that only the more severe cases are hospitalized among all patients who are brought to the emergency department. More and more patients are seen in the emergency room and because of the lack of resources associated with this increase in demand, only the more severe cases are admitted. In addition, the TBI clientele hospitalized in the urban MUHC-MGH acute care setting was found to be more and more complex over this period and included patients with previous medical, psychological and social problems which may also have an impact on the ISS scores and admission rates. On the other hand, TBI severity (GCS scores) tended to decrease over this time period and was found to be influenced by age. The results indicated that the risk of having a TBI of greater severity (lower GCS score) was greater for those under the age of 70 . Since more and more patients aged over 70 years were admitted during this period, it would seem that age contributed to the GCS score increase in the years studied. Thus, the increase in age contributed to the decrease in TBI severity but also to the rise in admissions which could also be a result of an increase in trauma severity and in premorbid complexity factors.

In regards to outcome, a tendency towards a slight decrease in the GOSE score (more severe) was seen over the years spanning between 2000 and 2011. This finding could be explained by the ageing of the TBI population being admitted. In fact, age has been considered as a variable influencing outcome, with the older person having a less favourable outcome than their younger counterpart ${ }^{16,17}$. Mortality and morbidity due to brain injury in the elderly population is a growing clinical problem: among older patients, those over 70 years have a considerably higher risk of both ${ }^{18}$. This increase in the number of older patients with TBI presenting with fragile health and more comorbidities needs to be taken into consideration when planning discharge from the acute care setting as these patients often require more medical, nursing as well as acute in-patient rehabilitation or long-term care services.

With regard to discharge destination, a slight decrease in the proportion of discharges home and of deaths and a slight increase in the proportion of patients sent to either inpatient or outpatient rehabilitation were found. The findings regarding outcome are in keeping with previous research. The percentage of mortality in the present study (11\%) was similar to other Canadian data reporting $8 \%(\mathrm{CIHI})$. Moreover, it has been observed that $54 \%$ of patients needed at least occasional care after discharge from hospital ${ }^{11}$ and most patients with TBI were referred to post-acute care and rehabilitation whereas a majority had a moderate or severe disability ${ }^{6}$. Several factors such as the presence of a caregiver may have a significant influence on discharge planning following TBI. The results of the current study did not allow us to determine the differences between patients who had a caregiver and those who did not have someone to take care of them upon discharge. This information was not provided in the medical chart of the patient. However, further research on the impact of a caregiver on discharge planning should be pursued.

One limitation of this study is the lack of information regarding patients with mild TBI that were seen in the emergency department but were not hospitalized. The hospitalized patients with TBI are obviously more severely injured and the cohort of this investigation including only the hospitalized patients was not necessarily representative of all TBI cases. In fact, the literature claims that the majority of all TBI cases are considered to be mild $(80 \%)^{19,20}$. Thus, one should refrain from generalizing the results of this study to all TBI cases as this survey is not representative of all TBI clientele. Moreover, there are various degrees of missing data because of the retrospective nature of this work, but, the number of patients in each group remains high which probably limits the impact on the analyses. Finally, other information pertinent to some of the results is missing and limits their interpretation. These include the reasons of mortality, presence or not of any delay to intervention measured in part by the distance between the hospital and the scene of the accident, the presence of a caregiver which may influence LOS and discharge destination and the demographic, psychosocial or economic factors related to our institution, services or clientele which also may have had an impact on outcome. The MUHC-MGH is an urban institution which is more likely to admit patients with large disparities in socioeconomic status. Moreover, higher rates of crime and violence in cities and the presence of marginalized populations with high risk behaviors who tend to live in urban areas ${ }^{21}$ may also have had an influence on the characteristics of the clientele admitted.

In conclusion, based on the findings of this study, if the trends continue, an increase in the number of patients hospitalized with TBI can be expected in the future, especially for those 70-yearsold and over, a clientele that has a greater chance of poorer outcome. Moreover, overall ISS scores have increased and, if we compound an increase in the number of medical, social and psychological premorbid factors, the care of these patients will become more and more complicated. Thus, administrators and policy makers will need to plan for future resources taking into account this eventual source of greater burden and costs related to a higher number of cases per year and an increase in patient age and complexity. Based on these findings, a multidisciplinary acute rehabilitation team with a comprehensive approach should be involved in the acute care setting to offer a high level of care to patients with TBI. Also, special prevention programs are needed to lower the risk of falls in the elderly. 


\section{REFERENCES}

1. Jumisko E, Lexell J, Soderberg S. Living with moderate or severe traumatic brain injury: The meaning of family members' experiences. J Fam Nurs. 2007;13:353-69.

2. Faul M, Xu L, Wald MM, Coronado VG. Traumatic brain injury in the United States: emergency department visits, hospitalizations and deaths 2002-2006. Centers for Disease Control and Prevention (www.cdc.gov/traumatic brain injury/). Atlanta: Centers for Disease Control and Prevention, National Center for Injury Prevention and Control;c2012-13 (update 2013 March 18; cited 2013 Aug 15). Available from www.cdc.gov.

3. Canadian Institute for Health Information (CIHI). Ottawa: Hospitalizations due to traumatic brain injuries down $35 \%$ over a decade. CIHI (update 2006 August 30; cited 2006 Aug 30). Available from: http://secure.cihi.ca/cihiweb/disp.

4. Colantonio A, Croxford R, Farooq S, et al. Trends in hospitalization associated with traumatic brain injury in a publicly insured population, 1992-2002. J Trauma. 2009;66(1):179-83.

5. Thurman D, Guerrero J. Trends in hospitalization associated with traumatic brain injury. JAMA. 1999;282(10):954-7.

6. Jacobsson LJ, Westerberg M, Lexell J. Demographics, injury characteristics and outcome of traumatic brain injuries in northern Sweden. Acta Neurol Scand. 2007;116(5):300-6.

7. Judd FK, Jackson HJ, Komiti A, et al. High prevalence disorders in urban and rural communities. Aust N Z J Psychiatry. 2002;36 (1):104-13

8. Freudenberg N. Health promotion in the city: a review of current practice and future prospects in the United States. Annu Rev Publ Health. 2000;21:473-503.

9. Jennett B, Snoek J, Bond MR, et al. Disability after severe head injury: observations on the use of the Glasgow Outcome Scale. J Neurol Neurosurg Psychiatry. 1981;44:285-93.

10. Baldo V, Marcolongo A, Floreani A, et al. Epidemiological aspect of traumatic brain injury in Northeast Italy. Eur J Epidemiol. 2003;18(11):1059-63.
11. Koskinen S, Alaranta H. Traumatic brain injury in Finland 19912005: a nationwide register study of hospitalized and fatal TBI. Brain Inj. 2008;22(3):205-14.

12. Statistics Canada. Ottawa: Annual demographical estimates: Canada (cited $2010 \mathrm{Jul}$ 1). Available from:http://www.stat.can.gc.ca

13. Pentland B, Jones PA, Roy CW, et al. Head injury in the elderly. Age Ageing. 1986;15:193-202.

14. Slewa-Younan S, Baguley IJ, Heriseanu R, et al. Do men and women differ in their course following traumatic brain injury? A preliminary prospective investigation of early outcome. Brain Inj. 2008;22:183-91.

15. Seidler RD, Bernard JA, Burutolu TB, et al. Motor control and aging: Links to age-related brain structural, functional, and biochemical effects. Neurosci Biobehav Rev. 2010 Apr;34(5): 721-33.

16. Hukkelhoven CW, Steyerberg EW, Rampen AJ, et al. Patient age and outcome following severe traumatic brain injury: An analysis of 5,600 patients. J Neurosurg. 2003;99:666-73.

17. Susman M, DiRusso SM, Sullivan T, et al. Traumatic brain injury in the elderly: Increased mortality and worse functional outcome at discharge despite lower injury severity. J Trauma. 2002;53: 219-23.

18. Gaetani P, Revay M, Sciacca S, et al. Traumatic brain injury in the elderly: considerations in a series of 103 patients older than 70 . J Neurosurg Sci. 2012;56(3):231-7.

19. Cassidy JD, Carroll LJ, Peloso PM. Incidence, risks factors and prevention of mild traumatic brain injury: results of the WHO Collaborating Centre Task Force on mild Traumatic Brain injury. J Rehabil Med. 2004;43:28-60.

20. Kraus J, Schaffer K, Ayers K, et al. Physical complaints, medical service use, and social and employment changes following mild traumatic brain injury: a 6-month longitudinal study. J Head Trauma Rehab. 2005;20:239-56.

21. Geronimus AT. To mitigate, resist, or undo: addressing structural influences on the health of urban populations. Am J Public Health. 2000;90:867-72. 